\title{
Pengaruh kompres hangat terhadap intensitas nyeri persalinan kala I fase aktif
}

\author{
Suyani Suyani* \\ Program Studi Kebidanan Program Profesi Bidan, Universitas 'Aisyiyah Yogyakarta, \\ Yogyakarta - Indonesia
}

\begin{abstract}
Pain is an integral part of labor and childbirth which is normal due to physiological and psychological factors. Labor pain can affect uterine contractions through secretion of catecholamine and cortisol levels which increase sympathetic nervous system activity, changes in blood pressure, heart rate, breathing, and consequently affect labor duration. This study aims to determine the effect of warm compresses on the intensity of labor in the first phase of active labor. The design of this study was quasi-experimental with one group pre-test and post-test design. The population in this study were all labor women at BPM Tri Rahayu Setyaningsih Sleman Yogyakarta, with incidental sampling techniques and 18 samples were obtained. A compress was carried out in the lower abdomen using hot bladders. Data analysis using Paired $T$ test. Based on the research results obtained, the mean pain score before treatment was 8.66 and the mean pain score after treatment was 5.83. The results of statistical analysis of different pain intensity tests before and after treatment showed a significant difference $(p=0,000 ; 95 \% \mathrm{Cl}-3,352-(-2,314)$. This shows that warm compresses can reduce the intensity of pain in labor during the active phase. warmth can be used as one way to reduce the intensity of labor pain.
\end{abstract}

Keywords: labor pain; pain intensity; warm compresses

Nyeri merupakan bagian integral dari persalinan dan melahirkan yang normal terjadi disebabkan oleh faktor fisiologis dan psikis. Nyeri persalinan dapat mempengaruhi kontraksi uterus melalui sekresi kadar katekolamin dan kortisol yang menaikkan aktivitas sistem saraf simpatis, perubahan tekanan darah, denyut jantung, pernapasan dan akibatnya mempengaruhi lama persalinan. Penelitian ini bertujuan untuk mengetahui pengaruh kompres hangat terhadap intensitas nyeri persalinan kala I fase aktif. Desain Penelitian ini quasi eksperiment dengan rancangan one group pre test and post test design. Populasi dalam penelitian ini semua ibu bersalin di BPM Tri Rahayu Setyaningsih Sleman Yogyakarta, dengan teknik pengambilan sampel insidental dan didapatkan 18 sampel kompres dilakukan di bagian perut bawah dengan menggunakan buli-buli panas. Analisis data menggunakan Paired $\mathrm{T}$ test. Berdasarkan hasil penelitian yang diperoleh, rerata skor nyeri sebelum perlakuan adalah 8,66 dan rerata skor nyeri sesudah perlakuan adalah 5,83 . Hasil analisis statistik uji beda intensitas nyeri sebelum dan sesudah perlakuan didapatkan hasil perbedaan yang bermakna $(p=0,000 ; 95 \% \mathrm{Cl}-3,352-(-2,314)$. Hal ini menunjukkan bahwa kompres hangat dapat menurunkan intensitas nyeri nyeri persalinan kala I fase aktif. Kompres hangat dapat digunakan sebagai salah satu cara dalam mengurangi intensitas nyeri persalinan.

Kata Kunci: intensitas nyeri; kompres hangat; nyeri persalinan

\footnotetext{
*Korespondensi Penulis: Suyani (email: suyanibasyar@unisayogya.ac.id), Jl. Siliwangi (Ring Road Barat) No. 63 Mlangi, Nogotirto,
} Gamping, Sleman, Yogyakarta. 55292. 


\section{Pendahuluan}

Nyeri persalinan dapat mempengaruhi kontraksi uterus melalui sekresi kadar katekolamin dan kortisol yang menaikkan aktivitas sistem saraf simpatis, perubahan tekanan darah, denyut jantung, pernapasan dan akibatnya mempengaruhi lama persalinan. Nyeri juga dapat menyebabkan aktivitas uterus tidak terkoordinasi yang akan mengakibatkan persalinan lama. Adapun nyeri persalinan yang berat dan lama dapat mempengaruhi verifikasi sirkulasi maupun metabolisme yang harus segera diatasi karena dapat menyebabkan semakin lamanya waktu persalinan yang akan membahayakan nyawa ibu maupun janin (Lowdermilk, Perry, Cashion, Alden, \& Olshansky, 2012).

Intensitas nyeri yang dirasakan bergantung pada beberapa faktor, seperti intensitas dan lamanya kontraksi rahim, besarnya pembukaan mulut rahim, regangan jalan lahir bagian bawah, umur, paritas dan jumlah anak yang pernah dilahirkan, besarnya janin dan kondisi psikis ibu. Riset yang dilakukan Ye, Jiang, \& Ruan (2011) menunjukkan bahwa ibu yang bersalin untuk pertama kali akan mengalami nyeri yang lebih berat dibandingkan dengan ibu yang melahirkan untuk kedua kalinya, intensitas kontraksi pada persalinan yang pertama cenderung lebih tinggi pada awal persalinan. Juga pada kemacetan persalinan akibat janin yang besar atau jalan lahir yang sempit, pasien mengalami rasa nyeri yang lebih hebat daripada persalinan normal. Kelelahan dan kurang tidur berpengaruh juga terhadap toleransi ibu dalam menghadapi rasa nyeri (Zwelling, Johnson, \& Allen, 2006).
Rasa nyeri persalinan yang tinggi dapat menimbulkan kecemasan terutama pada ibu primigravida. Berdasarkan penelitian yang dilakukan oleh Klomp, de Jonge, Hutton, dan Lagro-Janssen di Belanda pada tahun 2013, menyebutkan bahwa masih banyak ibu primigravida yang saat persalinan belum mendapat tindakan untuk mengurangi nyeri, yaitu sekitar $85,5 \%$. Adanya nyeri saat bersalin meningkatkan kecemasan pada ibu yang dapat meningkatkan risiko terjadinya persalinan lama. Persalinan lama merupakan salah satu penyebab perdarahan setelah persalinan dimana uterus tidak dapat berkontraksi secara optimal dikarenakan otot-otot uterus mengalami kelemahan setelah lama berkontraksi, dimana $30 \%$ penyebab kematian ibu bersalin adalah perdarahan (Prata et al., 2011).

Kompres hangat merupakan salah satu metode non farmakologi yang dianggap sangat efektif dalam menurunkan nyeri atau spasme otot. Panas dapat dialirkan melalui konduksi, konveksi, dan konversi. Nyeri akibat memar, spasme otot, dan arthritis berespon baik terhadap peningkatan suhu karena dapat melebarkan pembuluh darah dan meningkatkan aliran darah lokal. Oleh karena itu, peningkatan suhu yang disalurkan melalui kompres hangat dapat meredakan nyeri dengan menyingkirkan produk-produk inflamasi, seperti bradikinin, histamin, dan prostaglandin yang akan menimbulkan rasa nyeri lokal (Price \& Wilson, 2006). BPM Tri Rahayu Setyaningsih dalam mengatasi nyeri persalinan menggunakan metode relaksasi nafas Panjang, tetapi jika dilakukan tidak tepat maka akan menimbulkan keinginan untuk mengejan lebih kuat meskipun pembukaan serviks belum lengkap. 


\section{Metode Penelitian}

Penelitian ini menggunakan rancangan kuantitatif dengan metode eksperimen (quasy experimental design) atau eksperimen. Populasi dalam penelitian ini adalah semua ibu bersalin kala I fase aktif di BPM TRS Cangkringan Sleman. Teknik pengambilan sampel pada penelitian ini adalah sampling insidental dengan waktu penelitian dua bulan. Jumlah sampel dalam penelitian ini adalah 18 ibu bersalin yang didapat selama dua bulan, dengan kriteria sampel adalah bersedia menjadi responden, kehamilan tunggal, presentasi belakang kepala, usia antara 20-35 tahun, usia kehamilan 37 minggu atau lebih, dan memasuki fase aktif yaitu $\geq 4 \mathrm{~cm}$.

Prosedur pengumpulan data dalam penelitian ini adalah sebagai berikut, Semua ibu bersalin yang datang ke BPM TRS dilakukan skrining sesuai kriteria inklusi dan eksklusi lalu diberikan penjelasan terkait penelitian, jika setuju maka responden menandatangani surat persetujuan menjadi responden. Ibu bersalin dinilai skala nyerinya dengan menggunakan Numeric Rating Scale (NRS), lalu diberikan kompres hangat dengan menggunakan buli-buli hangat yang diisi air hangat dengan suhu $32^{\circ} \mathrm{C}$ dibagian perut dan punggung yang disertai relaksasi nafas dalam sebagai perawatan standar selama 30 menit ketika uterus berkontraksi, setelah itu dinilai ulang skala nyerinya. Semua informasi yang didapat dicatat pada lembar observasi. Uji analisis data yang digunakan adalah Paired TTest.

\section{Hasil dan Pembahasan}

Mayoritas Pendidikan responden dalam penelitian ini adalah berpendidikan SMA sejumlah 8
$(44,4 \%)$. Pendidikan berhubungan dengan persepsi seseorang dalam mengatasi nyeri, semakin tinggi pendidikan seseorang maka semakin bias mengatasi nyeri persalinan. Mayoritas usia responden berumur 20-25 tahun dan 26-30 tahun yang berjumlah sama yaitu masing-masing 7 (38,9\%). Umur ibu yang semakin matang akan lebih mudah mengatasi nyeri karena dengan bertambahnya umur maka semakin dewasa dalam menghadapi situasi dan kondisi apapun pada dirinya. Rata-rata paritas dalam penelitian ini adalah 2 sebanyak 8 (44,4\%). Paritas berhubungan dengan nyeri persalinan, ibu yang sudah pernah melahirkan akan lebih mudah dalam mengatasi nyeri yang dialami. Mayoritas pembukaan serviks responden diawal penelitian adalah 7-9 cm sebanyak 16 (88,89\%). Semakin banyak pembukaan serviks maka akan semakin berat nyeri yang dirasakan (Afritayeni, 2017).

\section{Uji Normalitas Data}

Tabel 2. Menampilkan hasil distribusi data intensitas nyeri sebelum dan sesudah perlakuan pada responden menyatakan berdistribusi normal dengan $p$ value $>0,05$, hal ini menunjukkan bahwa uji beda dapat menggunakan paired $t$ test.

\section{Analisis Bivariat Pengaruh kompres hangat terhadap intensitas nyeri persalinan kala I fase aktif}

Hasil rata-rata intensitas nyeri sebelum dikompres adalah 8,66 dan setelah dilakukan kompres intensitas nye rinya didapatkan ratarata menurun menjadi 5,83 . Terlihat perbedaan nilai mean antara sebelum dikompres dengan sesudah dikompres adalah -2,83 dengan standar 
deviasi 1,043. Hasil uji statistik didapatkan nilai $p$ value 0,000 maka dapat disimpulkan ada perbedaan yang signifikan antara intensitas nyeri sebelum dan sesudah dilakukan kompres hangat.

Hasil penelitian ini sesuai dengan penelitian oleh Manurung et al. (2013) yang menyatakan bahwa kompres hangat dapat mengurangi intensitas nyeri persalinan, setelah intervensi selama 20 menit intensitas nyeri persalinan pada kelompok intervensi terdapat penurunan 2,07 point setiap responden. Hal ini sejalan dengan teori yang disampaikan Lowdermilk et al., (2012) yang menjelaskan bahwa kompres hangat dapat mengurangi nyeri karena kompres dapat memberikan sensasi nyaman dan dapat menghambat impuls nyeri dari sumber nyeri ke otak.

Tabel 1.

Distribusi Frekuensi

\begin{tabular}{ll}
\hline Karakteristik & Jumlah \\
$\mathrm{N}(\%)$ \\
\hline Tingkat Pendidikan & $1(5,6)$ \\
SD & $3(16,7)$ \\
SMP & $8(44,4)$ \\
SMA & $6(33,3)$ \\
PT & $7(38,9)$ \\
\hline Umur & $7(38,9)$ \\
$20-25$ & $4(22,2)$ \\
$26-30$ & \\
$31-35$ & $6(33,3)$ \\
\hline Paritas & $8(44,4)$ \\
1 & $4(22,2)$ \\
2 & \\
3 & $2(11,11)$ \\
\hline Pembukaan Serviks & $16(88,89)$ \\
$4-6$ & \\
\hline
\end{tabular}

Tabel 2.

Uji Normalitas Data Intensitas Nyeri

\begin{tabular}{ll}
\hline Intensitas nyeri & $P$ value \\
\hline Sebelum & 0,076 \\
Sesudah & 0,587 \\
\hline
\end{tabular}

Tabel 3.

Uji Paired T test antara intensitas Nyeri sebelum dan sesudah perlakuan

\begin{tabular}{|c|c|c|c|c|c|c|}
\hline & \multicolumn{2}{|c|}{ Intensitas Nyeri \pm SD } & \multirow[t]{2}{*}{$\Delta$ Mean } & \multirow[t]{2}{*}{$\mathrm{T}$} & \multirow[t]{2}{*}{ Pvalue } & \multirow[t]{2}{*}{ Cl $95 \%$} \\
\hline & Pre & Post & & & & \\
\hline Perlakuan & $8,66 \pm 0,97$ & $5,83 \pm 1,4$ & $-2,83$ & 11,523 & 0,000 & $-3,352-(-2,314)$ \\
\hline
\end{tabular}


Pemberian kompres hangat pada ibu bersalin efektif menurunkan intensitas nyeri dengan tanpa memberikan efek samping jika dibandingkan mengurangi nyeri dan mengurangi pegal di punggung dan ketegangan, sehingga ibu bersalin menjadi rileks dan menikmati persalinannya (Judha \& Sudarti, 2012).

Intensitas nyeri persalinan sulit diukur, karena merupakan perasaan subjektif yang alami. Peningkatan ambang nyeri berperan pada pasien untuk mengurangi rasa nyeri yang meningkat saat persalinan. Nyeri yang dirasakan ibu terjadi karena adanya mekanisme persalinan. Impuls saraf, yang dihasilkan oleh stimulus nyeri, menyebar di sepanjang serabut saraf perifer aferen. Transmisi stimulus nyeri berlanjut di sepanjang serabut saraf aferen sampai transmisi tersebut berakhir di bagian kornu dorsalis medulla spinalis. Impuls nyeri ditransmisikan lebih jauh ke dalam sistem saraf pusat dan dipersepsikan di otak (Potter, Perry, Stockert, \& Hall, 2016).

Kompres hangat dapat menurunkan persepsi nyeri dengan menstimulasi sistem kontrol desenden, sehingga lebih sedikit stimuli nyeri yang ditransmisikan ke otak. Jika impuls nyeri dihantar ke otak, terdapat pusat korteks yang lebih tinggi di otak yang memodifikasi persepsi nyeri di mana alur saraf desenden akan melepaskan opiate endogen, seperti endorfin dan dinorfin, yaitu suatu pembunuh nyeri alami yang berasal dari tubuh (Lowdermilk et al., 2012).

Hal ini menunjukkan bahwa kompres hangat dapat menurunkan nyeri secara bermakna, sehingga dapat dijadikan sebagai salah satu upaya untuk mengurangi nyeri pada ibu bersalin di klinis. Kompres hangat yang dilakukan di daerah sakral akan menghalangi impuls nyeri dari uterus ke otak sehingga persepsi ibu tentang nyeri akan berkurang. Rangsangan nyeri yang ditimbulkan oleh kontraksi rahim diatur disumsum tulang belakang oleh sel-sel saraf yang bertindak sebagai gerbang yang mencegah atau memfasilitasi lewatnya impuls ke otak (Melzack \& Wall, 1965).

Persalinan merupakan salah satu pengalaman yang penuh dengan perasaan nyeri dan sangat bermakna dalam kehidupan wanita. Rasa nyeri yaitu istilah subjektif dari perasaan yang tidak nyaman, rasa sakit. Nyeri merupakan perasaan yang sangat subjektif. Memahami penderitaan wanita terhadap nyeri saat persalinan, penting untuk menentukan manajemen yang tepat. Berbagai metode dikembangkan saat ini untuk mengurangi penderitaan wanita saat persalinan, baik secara farmakologis maupun nonfarmakologis. Metode pengurangan nyeri yang dibutuhkan adalah yang efektif dan tidak mempunyai efek samping (Jones et al., 2012). Usaha mengurangi intensitas nyeri pada ibu bersalin menggunakan metode nonfarmakologi terbukti memberikan dampak positif pada ibu bersalin, seperti yang disampaikan Gayeski, Brüggemann, Monticelli, dan dos Santos (2015).

\section{Kesimpulan}

Berdasarkan penelitian yang dilakukan terhadap 18 ibu bersalin di BPM Tri Rahayu Setyaningsih didapatkan hasil bahwa terjadi penurunan rerata intensitas nyeri pada ibu bersalin kala I fase aktif dari skor 8,66 turun menjadi 5,85. Setelah dilakukan uji statistik terdapat perbedaan yang siknifikan dengan $p$ value 0,000 dan mean 
difference $-2,83(95 \% \mathrm{Cl}-3,352-(-2,314))$, hal ini menunjukkan bahwa kompres hangat berpengaruh menurunkan intensitas nyeri ibu bersalin kala I fase aktif.[]

\section{Daftar Pustaka}

Afritayeni, A. (2017). Hubungan umur, paritas dan pendamping persalinan dengan intensitas nyeri persalinan kala I. Jurnal Endurance: Kajian IImiah Problema Kesehatan, 2(2), 178-185.

Gayeski, M. E., Brüggemann, O. M., Monticelli, M., \& dos Santos, E. K. A. (2015). Application of nonpharmacologic methods to relieve pain during labor: The point of view of primiparous. Pain Management Nursing, 16(3), 273-284. https://doi.org/ 10.1016/j.pmn.2014.08.006

Jones, L., Othman, M., Dowswell, T., Alfirevic, Z., Gates, S., Newburn, M., ... Neilson, J. P. (2012). Pain management for women in labour: An overview of systematic reviews. Cochrane Database of Systematic Reviews, (3), CD009234. https://doi.org/10.1002/ 14651858.CD009234.pub2

Judha, M., \& Sudarti, F. A. (2012). Teori pengukuran nyeri dan nyeri persalinan. Yogyakarta: Nuha Medika.

Klomp, T., de Jonge, A., Hutton, E. K., \& LagroJanssen, A. L. M. (2013). Dutch women in midwife-led care at the onset of labour: Which pain relief do they prefer and what do they use? BMC Pregnancy and Childbirth, 13(1), 230. https://doi.org/10.1186/14712393-13-230
Lowdermilk, D. L., Perry, S. E., Cashion, M. C., Alden, K. R., \& Olshansky, E. (2012). Maternity and women's health care. St. Louis: Mosby Inc.

Manurung, S., Nuraeni, A., Lestari, T. R., Soleha, I., Suryati, S., Nurhaeni, H., ... Rahmawaty, E. (2013). Pengaruh teknik pemberian kompres hangat terhadap perubahan skala nyeri persalinan pada klien Primigravida. Jurnal Health Quality, 4(1-8).

Melzack, R., \& Wall, P. D. (1965). Pain mechanisms: A new theory. Science, 150(3699), 971-979. https://doi.org/10.1126/science.150.3699.9 71

Potter, P. A., Perry, A. G., Stockert, P., \& Hall, A. (2016). Fundamentals of nursing (E-Book). St. Louis: Elsevier Health Sciences.

Prata, N., Hamza, S., Bell, S., Karasek, D., Vahidnia, F., \& Holston, M. (2011). Inability to predict postpartum hemorrhage: Insights from Egyptian intervention data. BMC Pregnancy and Childbirth, 11(1), 97. https://doi.org/ 10.1186/1471-2393-11-97

Price, \& Wilson. (2006). Patofisiologi konsep klinis proses-proses penyakit. Jakarta: EGC Penerbit Buku Kedokteran.

Ye, H., Jiang, Y., \& Ruan, Z. (2011). Relationship between factors of labour pain and delivery outcomes. Zhonghua fu chan ke za zhi, 46(10), 753-757. Diambil dari http://www. ncbi.nlm.nih.gov/pubmed/22321349

Zwelling, E., Johnson, K., \& Allen, J. (2006). How to implement complementary therapies for laboring women. MCN, The American Journal of Maternal/Child Nursing, 31(6), 364-370. https://doi.org/10.1097/00005721200611000-00006 